\title{
Differences between 1999 and 2010 across the Falkland Plateau: fronts and water masses
}

\author{
M. Dolores Pérez-Hernández ${ }^{1,5}$, Alonso Hernández-Guerra ${ }^{1}$, Isis Comas-Rodríguez ${ }^{1}$, Verónica M. Benítez-Barrios ${ }^{1}$, \\ Eugenio Fraile-Nuez ${ }^{2}$, Josep L. Pelegrí ${ }^{3}$, and Alberto C. Naveira Garabato ${ }^{4}$ \\ ${ }^{1}$ Instituto de Oceanografía y Cambio Global (IOCAG), Universidad de Las Palmas de Gran Canaria (ULPGC), \\ Las Palmas, Spain \\ ${ }^{2}$ Centro Oceanográfico de Canarias, Instituto Español de Oceanografía, Santa Cruz de Tenerife, Spain \\ ${ }^{3}$ Institut de Ciències del Mar, Consejo Superior de Investigaciones Científicas, Barcelona, Spain \\ ${ }^{4}$ University of Southampton, National Oceanography Centre, Southampton, UK \\ ${ }^{5}$ Department of Physical Oceanography, Woods Hole Oceanographic Institution, Woods Hole, USA
}

Correspondence to: M. Dolores Pérez-Hernández (mdolores.perez@whoi.edu)

Received: 17 November 2016 - Discussion started: 13 December 2016

Revised: 6 June 2017 - Accepted: 7 June 2017 - Published: 7 July 2017

\begin{abstract}
Decadal differences in the Falkland Plateau are studied from the two full-depth hydrographic data collected during the ALBATROSS (April 1999) and MOC-Austral (February 2010) cruises. Differences in the upper $100 \mathrm{dbar}$ are due to changes in the seasonal thermocline, as the ALBATROSS cruise took place in the austral fall and the MOCAustral cruise in summer. The intermediate water masses seem to be very sensitive to the wind conditions existing in their formation area, showing cooling and freshening for the decade as a consequence of a higher Antarctic Intermediate Water (AAIW) contribution and of a decrease in the Subantarctic Mode Water (SAMW) stratum. The deeper layers do not exhibit any significant change in the water mass properties. The Subantarctic Front (SAF) in 1999 is observed at $52.2-54.8^{\circ} \mathrm{W}$ with a relative mass transport of $32.6 \mathrm{~Sv}$. In contrast, the SAF gets wider in 2010, stretching from 51.1 to $57.2^{\circ} \mathrm{W}$ (the Falkland Islands), and weakening to $17.9 \mathrm{~Sv}$. Changes in the SAF can be linked with the westerly winds and mainly affect the northward flow of Subantarctic Surface Water (SASW), SAMW and AAIW/Antarctic Surface Water (AASW). The Polar Front (PF) carries 24.9 Sv in 1999 $\left(49.8-44.4^{\circ} \mathrm{W}\right)$, while in $2010\left(49.9-49.2^{\circ} \mathrm{W}\right)$ it narrows and strengthens to $37.3 \mathrm{~Sv}$.
\end{abstract}

\section{Introduction}

The Antarctic Circumpolar Current (ACC) flows eastwards around the Antarctic continent, transporting roughly between 100 and $173 \mathrm{~Sv}\left(1 \mathrm{~Sv}=10^{6} \mathrm{~m}^{3} \mathrm{~s}^{-1} \approx 10^{9} \mathrm{~kg} \mathrm{~s}^{-1}\right.$; hereafter $\mathrm{Sv}$ will be the unit used) (Orsi et al., 1995; Cunningham et al., 2003; Donohue et al., 2016). Along its path, it connects the Atlantic, Pacific and Indian basins, exchanging heat and freshwater among other properties. Although convergence of net flux estimates has been achieved on basin scales (Ganachaud and Wunsch, 2003), the ACC flow into the Atlantic Ocean is critical to establish the magnitude and pathways of the Southern Ocean contribution to the deep global ocean ventilation.

Peterson and Whitworth III (1989) suggested that the Subantarctic Front (SAF) and the Polar Front (PF), where the major velocity bands of the ACC occur, turn northwestward across the Falkland Plateau to the west of the Maurice Ewing Bank, along the Patagonian continental slope. This was supported by Peterson (1992), who estimated the large contribution of the ACC to the Falkland Current (60$70 \mathrm{~Sv}$ ), revealing the importance of the overflow of southern waters to the South Atlantic boundary circulation. Peterson and Whitworth III (1989) located the SAF near $53^{\circ} \mathrm{W}$, as corroborated by Arhan et al. (2002), at a location where the ocean depth is $2000 \mathrm{~m}$. Several studies have later examined the path of the PF around the Maurice Ewing Bank (Trathan et al., 2000) and its branching around $49-50^{\circ} \mathrm{W}$ (Arhan et 

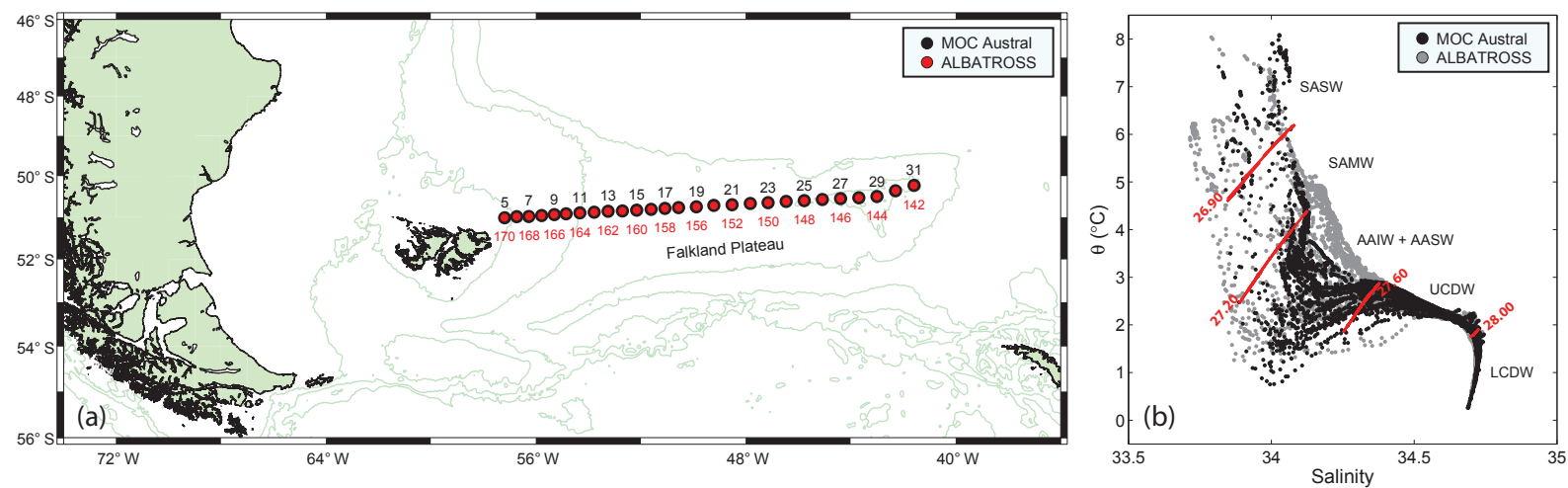

Figure 1. (a) Hydrographic stations across the Falkland Plateau carried out during the ALBATROSS (1999, red station numbers) and MOCAustral (2010, black station numbers) cruises. (b) $\theta-S$ diagram for both cruises. Red solid lines represent the $\gamma^{n}$ values $(26.90,27.20,27.60$ and $28.00 \mathrm{~kg} \mathrm{~m}^{-3}$ ) defining the different water masses in the region.

al., 2002), with a possible meandering of the front according to Naveira Garabato et al. (2002).

The first hydrographic cruise along the Falkland Plateau was carried out in 1999. The ALBATROSS (Antarctic Largescale Box Analysis and the Role of the Scotia Sea) cruise explored the ACC through the Drake Passage and the Scotia Sea (Fig. 1). The data of this cruise have been used to estimate relative transport, water masses, fluxes and mixing across the plateau (Naveira Garabato et al., 2003) and to provide a detailed explanation of the deep waters in the Scotia Sea (Naveira Garabato et al., 2002). Later on, this section was compared with hydrographic cruises carried out north and south of the Falkland Plateau to achieve a better knowledge of this area (Arhan et al., 2002; Smith et al., 2010). However, it is not until 2010 that this section is repeated.

In this study, the water masses, relative geostrophic velocities and transports across an almost zonal hydrographic section carried out in 2010 along the Falkland Plateau are evaluated. These data, together with the ALBATROSS cruise, are the only high-resolution hydrographic data available in the region. Thus, results from the 2010 cruise are compared with those obtained from the 1999 cruise in the same area (Naveira Garabato et al., 2003), with the objective of assessing possible relative transport and water mass differences between the two surveys. For changes in the relative transport, the position of the fronts and the season in which each cruise took place will be considered. Changes in water masses are decomposed into changes in the $\theta / S$ isobaric surfaces and results from the Bindoff and McDougall (1994) model.

\section{Data and methods}

The MOC-Austral cruise was carried out in February 2010 onboard the BIO Hespérides. As shown in Fig. 1a, 27 fulldepth conductivity, temperature and depth (CTD) stations were occupied across the Falkland Plateau, tracking along the casts previously conducted in between 41 and $57^{\circ} \mathrm{W}$ at the nominal latitude of $51^{\circ} \mathrm{S}$ during the ALBATROSS cruise in April 1999 (Naveira Garabato et al., 2003). With a spatial separation of 30 to $50 \mathrm{~km}$, temperature and salinity profiles were obtained using a SeaBird 911+ CTD with dual conductivity and temperature sensors. The CTD was sent to SeaBird for calibration before the cruise. The temperature sensor has an accuracy of $0.001{ }^{\circ} \mathrm{C}$. The conductivity sensors were calibrated on board with bottle sample salinities. To that end, water samples were analyzed on a Guildline AUTOSAL 8400B salinometer with accuracy better than 0.002 for single samples (salinity is expressed in the Practical Salinity Scale, UNESCO, 1981).

Relative geostrophic velocities and mass transports are estimated for both the ALBATROS and MOC-Austral cruises using the sea bottom as the level of no motion. The water column is divided into 18 neutral density layers following the work of Naveira Garabato et al. (2003) (see Table 1). Weddell Sea Deep Water (WSDW) is not found along the plateau; thus, its density layers are not considered here.

Bindoff and McDougall (1994) describe a model to evaluate the temperature and salinity variations in the water column. This model relates the temperature and salinity in both pressure and density changes through the following equation:

$$
\left.\frac{\mathrm{d} \psi}{\mathrm{d} t}\right|_{z}=\left.\frac{\mathrm{d} \psi}{\mathrm{d} t}\right|_{\gamma^{n}}-\left.\frac{\mathrm{d} p}{\mathrm{~d} t}\right|_{\gamma^{n}} \frac{\mathrm{d} \psi}{\mathrm{d} p},
$$

which shows that for a given property $(\psi$, temperature or salinity), the variations along isobaric levels $\left(\left.\frac{\mathrm{d} \psi}{\mathrm{d} t}\right|_{z}\right)$ can be described as the sum of changes along isoneutral surfaces $\left(\left.\frac{\mathrm{d} \psi}{\mathrm{d} t}\right|_{\gamma^{n}}\right)$ and changes due to vertical displacements of the density surfaces, referred to as heaving $\left(\left.\frac{\mathrm{d} p}{\mathrm{~d} t}\right|_{\gamma^{n}} \frac{\mathrm{d} \psi}{\mathrm{d} p}\right)$. This allows the comparison between the isobaric changes and the sum of the two decomposed components, which represent the variations of the water masses (warming and freshening) 
Table 1. SAF, PF and net geostrophic mass transport (Sv) per cruise and water mass. The last row shows the net transport, while the last column indicates the transport difference between cruises.

\begin{tabular}{|c|c|c|c|c|c|c|c|c|c|}
\hline & \multicolumn{3}{|c|}{ ALBATROSS (1999) } & \multicolumn{3}{|c|}{ MOC-Austral (2010) } & \multicolumn{3}{|c|}{ Difference (2010-1999) } \\
\hline & SAF & PF & Net & SAF & $\mathrm{PF}$ & Net & SAF & $\mathrm{PF}$ & Net \\
\hline SASW $\gamma^{n}<26.90$ & 3.2 & 2.0 & 4.5 & 1.9 & 1.6 & 2.3 & -1.3 & -0.4 & -2.2 \\
\hline SAMW $27.00<\gamma^{n}<27.20$ & 5.1 & 1.0 & 4.9 & 1.4 & 1.8 & 2.2 & -2.9 & 0.8 & -2.7 \\
\hline AAIW/AASW $27.30<\gamma^{n}<27.60$ & 15.5 & 8.3 & 16.8 & 10.9 & 9.7 & 11.8 & -4.6 & 1.4 & -5.0 \\
\hline UCDW $27.70<\gamma^{n}<28.00$ & 8.6 & 12.0 & 12.4 & 3.8 & 20.1 & 11.7 & -4.8 & 8.1 & -0.7 \\
\hline LCDW $28.05<\gamma^{n}$ & 0.1 & 1.6 & 0.3 & 0.0 & 4.1 & 1.7 & -0.1 & 2.5 & 1.4 \\
\hline Net & 32.6 & 24.9 & 38.9 & 17.9 & 37.3 & 29.7 & -14.7 & 12.4 & -9.2 \\
\hline
\end{tabular}
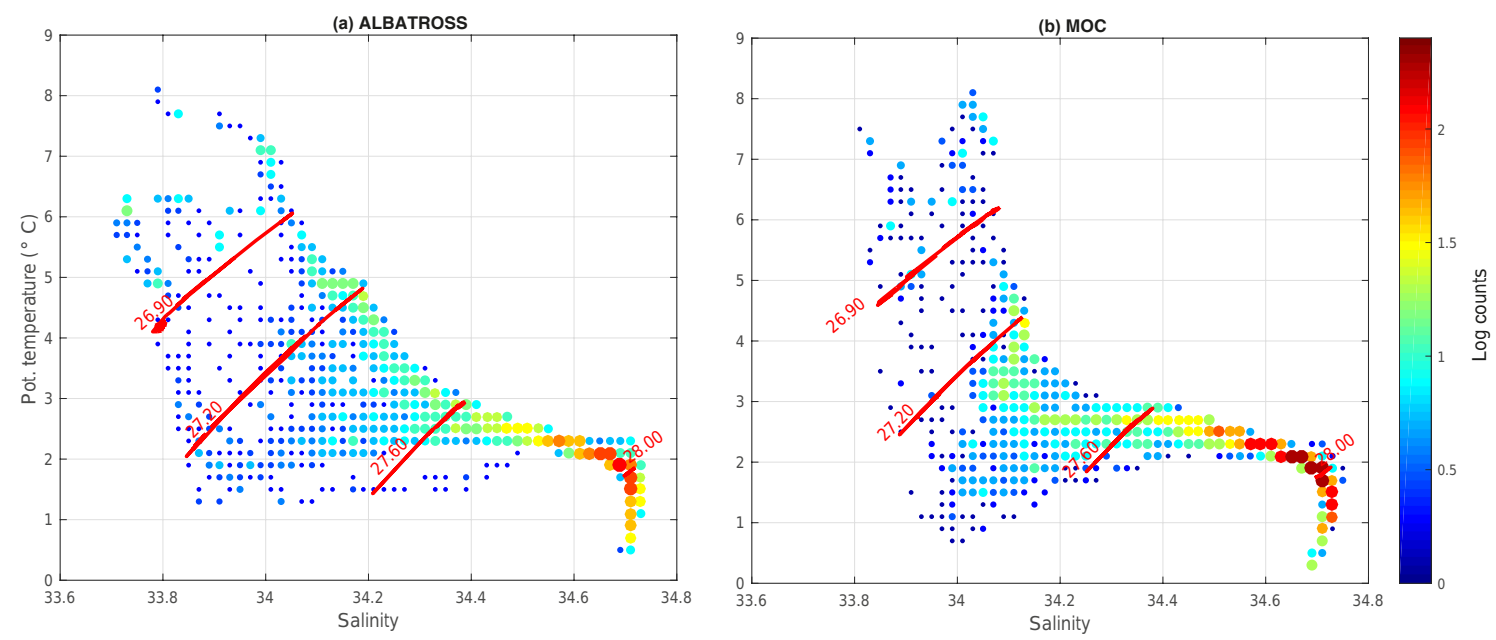

Figure 2. A volumetric potential temperature-salinity diagram for the (a) ALBATROSS and (b) MOC-Austral cruises. Red solid lines represent the $\gamma^{n}$ values $\left(26.90,27.20,27.60\right.$ and $\left.28.00 \mathrm{~kg} \mathrm{~m}^{-3}\right)$ defining the different water masses in the region. Dot size and color indicate the logarithm of counts.

and the heaving. To apply this methodology, temperature and salinity are interpolated onto a grid with a pressure interval of $20 \mathrm{dbar}$ (from 10 to $3500 \mathrm{dbar}$ ) and the following neutral density $\left(\mathrm{kg} \mathrm{m}^{-3}\right)$ values: from 26 to 27.6 each 0.02 , from 27.7 to 28 each 0.01 and from 28.005 to 28.5 each 0.005 . This vector is selected to properly represent the different structures found in the water column.

In addition, sea surface height (SSH) was downloaded from AVISO (http://www.aviso.oceanobs.com/, Dibarboure et al., 2015). Data between 10 and 20 February 2010 are used for the analysis of the MOC-Austral cruise results. Data of February and April from 1993 to 2016 are used to estimate the average seasonal geostrophic transport in each month.

\section{Results}

\subsection{Water masses}

Water masses in the study region are labeled following Naveira Garabato et al. (2003). The isoneutrals 26.90, 27.20, 27.60 and $28.00 \mathrm{~kg} \mathrm{~m}^{-3}$ (red solid lines in Fig. 1b) divide the water column into Subantarctic Surface Water (SASW), Subantarctic Mode Water (SAMW), Antarctic Intermediate Water (AAIW) mixed with Antarctic Surface Water (AASW), Upper Circumpolar Deep Water (UCDW) and Lower Circumpolar Deep Water (LCDW), respectively.

Figure 2 shows that, in both cruises, the Circumpolar Deep Water (CDW) is the most homogenous water mass. The UCDW in the ALBATROSS cruise presents a wider temperature range and it is less homogeneous than in the MOC-Austral cruise. Figure 2 also shows that the strata of AAIW + AASW and SAMW are quite different between cruises. The AAIW + AASW stratum of the MOC-Austral cruise presents a minimum that consists of temperatures below $1.2^{\circ} \mathrm{C}$ and salinities around 34 . This minimum indicates that the contribution of AAIW is higher in 2010 than in 1999. In contrast, in the same stratum, the ALBATROSS cruise shows a thicker layer of AASW. The SASW in 1999 reaches higher salinities and temperatures than in the MOC-Austral cruise (this can be better observed in Fig. 1b, grey dots). It is also worth mentioning the existing difference between the SAWM strata of both cruises, as the one of the ALBATROSS 


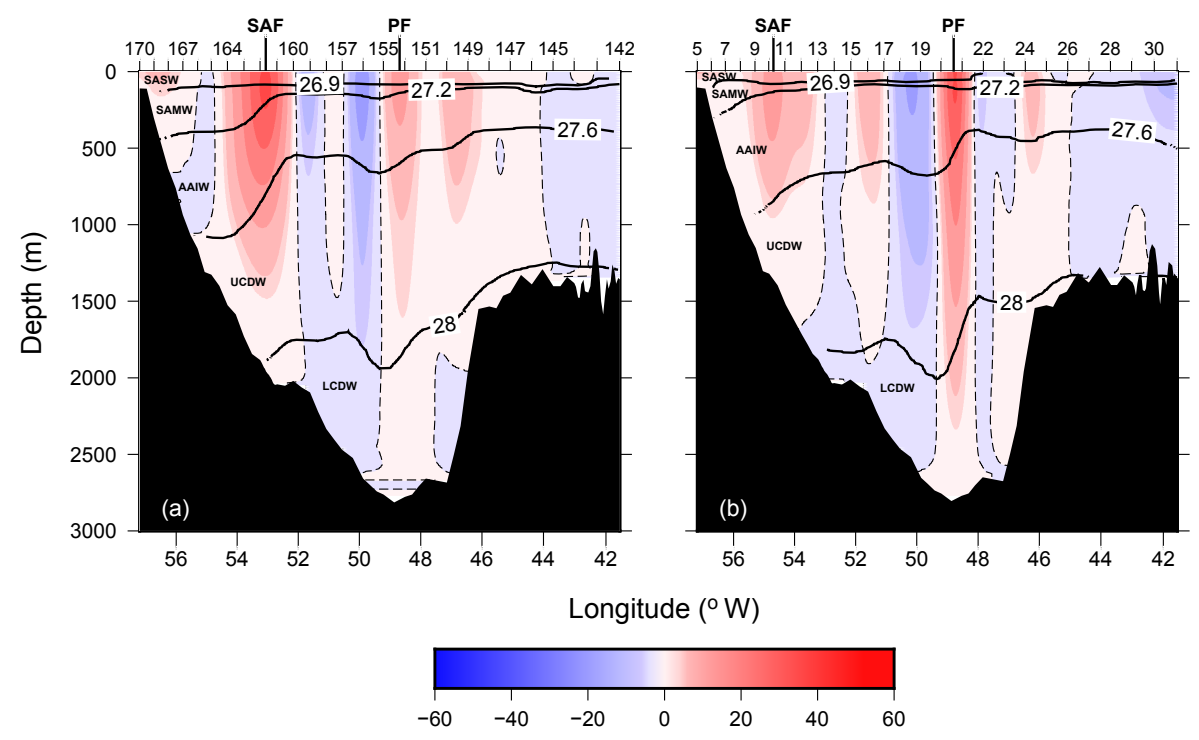

Figure 3. Geostrophic velocity ( $\mathrm{cm} \mathrm{s}^{-1}$, positive northward) relative to the bottom for (a) the ALBATROSS cruise and (b) the MOC-Austral cruise. Black dashed lines mark $0 \mathrm{~cm} \mathrm{~s}^{-1}$ velocities. Thick black lines stand for the representative isoneutrals $(26.90,27.20,27.60$ and $28.00 \mathrm{~kg} \mathrm{~m}^{-3}$ ) defining the water masses in the region. Station numbering and the front (SAF and PF) location are displayed on the top axis.

cruise has a wider range of salinities than the one of MOCAustral (Fig. 2). The upper layers are less comparable as the cruises took place in different seasons, which implies different precipitation/evaporation and winds that will directly affect the SASW stratum.

\subsection{Fronts}

In Fig. 3, the prominent slope of the $\gamma^{n}$ surfaces together with the intensified relative velocities point out the presence of the SAF and PF near their historically reported locations (Orsi et al., 1995). In 1999, a northward-flowing jet accompanies the SAF, extending the front's influence from the surface down to approximately $1500 \mathrm{~m}$ between 52.2 and $54.8^{\circ} \mathrm{W}$ (Fig. 3a, stations 160 to 165 ). In contrast, the SAF is displaced to the west in 2010, extending from the Falkland shore $\left(57.2^{\circ} \mathrm{W}\right.$ ) to $51.1^{\circ} \mathrm{W}$ (stations 5 to 17 ), and the horizontal density gradient and associated relative geostrophic velocities are weaker (Fig. 3b). Regarding the PF, its quasibarotropic presence and effect on the water column are most noticeable in 2010 (Fig. 3b, stations 20 and 21), when it intensifies, displaying the strongest flow to the north around $49.5^{\circ} \mathrm{W}$. Figure 3a shows how this front is weaker in 1999 , when it extends approximately between 44.4 and $49.8^{\circ} \mathrm{W}$ and no intense jets are triggered by its presence (stations 146 to 156 ).

It can be observed how these fronts are revealed by the sloping isoneutrals, suffering significant changes between the two oceanographic cruises. Therefore, it is important to determine which variations in potential temperature and salinity are due to water mass changes and which are caused by the displacement of the $\gamma^{n}$ surfaces.

\subsection{The $\theta / \mathrm{S}$ isobaric changes}

Figure 4 reveals that in the decade, the waters shallower than 50 dbar (roughly the SASW stratum) exhibit a significant increase in temperature and salinity, being $0.5^{\circ} \mathrm{C}$ and 0.12 , respectively (Fig. 4a-d). This surface increase is probably caused by the fact that the area was sampled in very different seasons: while the MOC-Austral cruise took place in the austral summer, the ALBATROSS cruise was carried out during the austral fall.

In the waters immediately beneath (from 50 to $500 \mathrm{dbar}$ ), the intermediate strata of SAMW and AAIW + AASW present a decrease in temperature of 0.8 and $0.4{ }^{\circ} \mathrm{C}$, respectively (Fig. 4a and b). In contrast, while salinity for the AAIW + AASW stratum also decreases by 0.01 , the salinity of the SAMW increases by 0.02 (Fig. $4 \mathrm{c}$ and d). In these intermediate strata, at roughly the location of the fronts (between stations 5-17 and 20-21), a remarkable decrease in temperature can be seen (Fig. 4a). In between stations 9-12, where the SAF stands, the UCDW exhibits a remarkable increase in salinity. This increase gets compensated in the average with the decrease observed throughout the stratum. The same is observed in the area of the PF, where an increase in salinity is registered at the UCDW and AAIW/AASW strata (Fig. 4c).

The UCDW and LCDW do not show any significant changes in temperature. The UCDW increases by 0.01 in salinity, while the LDCW does not show any significant difference in salinity (Fig. 4c and d). 

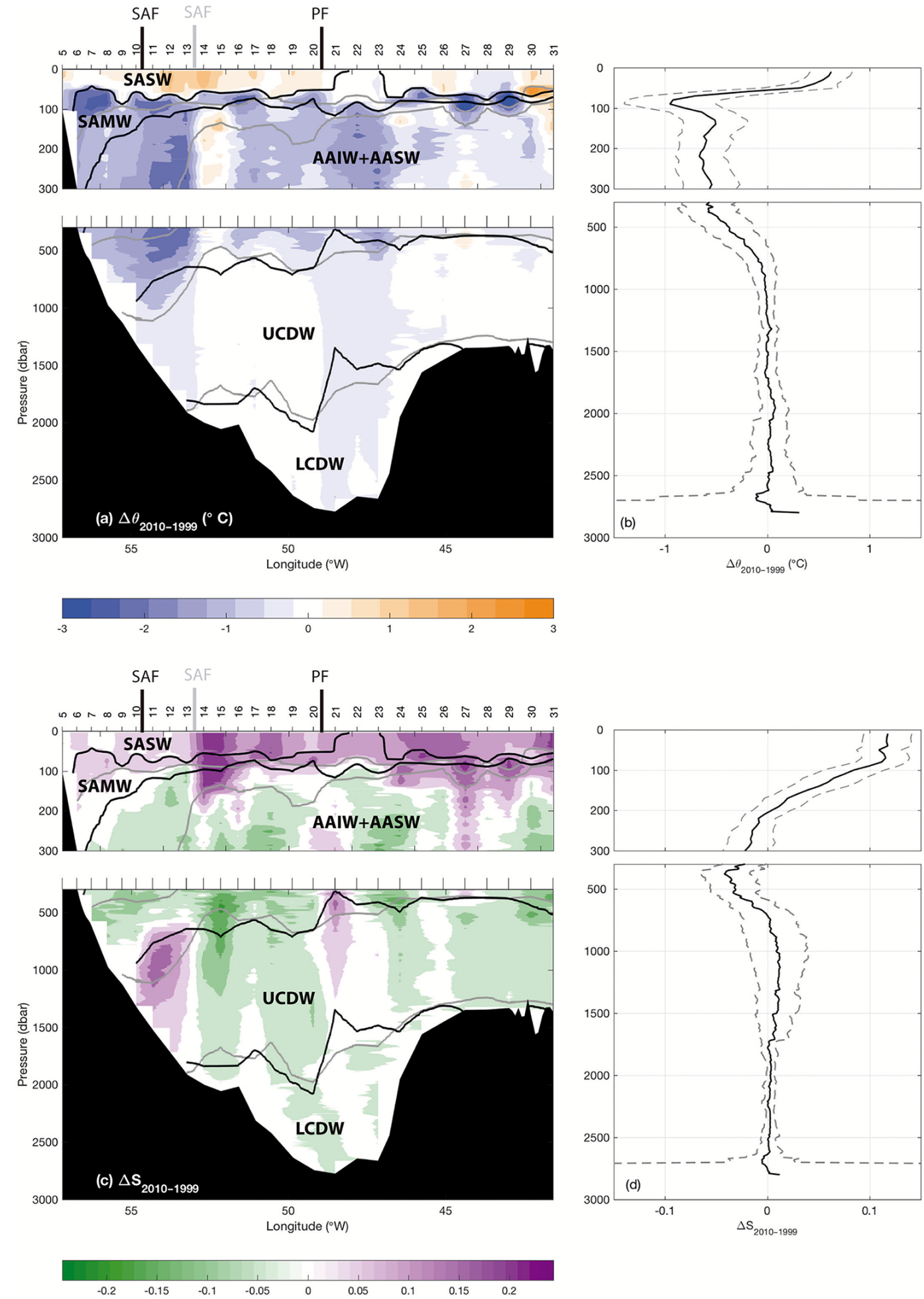

Figure 4. Vertical sections of differences in (a) potential temperature and (c) salinity in isobaric levels, for the 1999 and 2010 cruise. The lines superimposed over the vertical sections (grey lines for the 1999 section and black lines for the 2010 section) stand for the isoneutrals defining the different water masses in the region $\left(26.90,27.20,27.60\right.$ and $28.00 \mathrm{~kg} \mathrm{~m}^{-3}$ ). MOC-Austral station numbering and the front (SAF (grey 1999, black 2010) and PF) locations are displayed on the top axis. Side panels show the zonally averaged differences in temperature (b) and salinity (d), respectively (solid black lines), together with their $95 \%$ confidence interval based on a Student's $t$-test (dashed grey lines). 

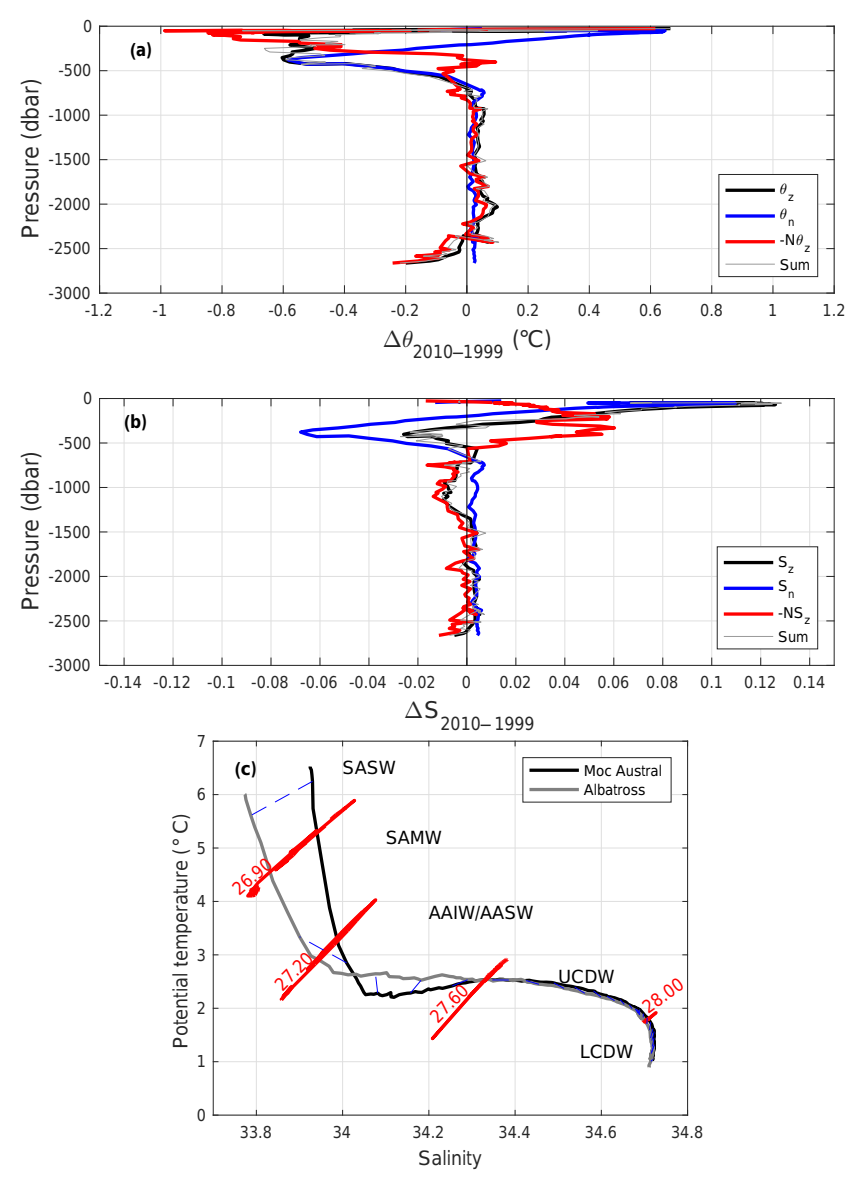

Figure 5. Isobaric changes from 1999 to $2010\left(\theta_{z}\right.$, black line) decomposed into changes along neutral surfaces $\left(\theta_{\mathrm{n}}, S_{\mathrm{n}}\right.$, blue line) and changes due to the vertical displacement of isoneutrals $\left(-\mathrm{N} \theta_{z}\right.$, $-\mathrm{NS}_{z}$, red line) for (a) potential temperature and (b) salinity. The grey line shows the sum of both components. The lower panel (c) shows the average profile of $\theta / S$ for each cruise together with the densities that divide the water column into the different water masses $\left(26.90,27.20,27.60\right.$ and $28.00 \mathrm{~kg} \mathrm{~m}^{-3}$, red lines) and the link in between points of equal pressure (dashed blue lines).

\subsection{Results of applying the Bindoff and McDougal (1994) analysis}

The temperature and salinity isobaric changes, their decomposition and the sum of the two components are plotted in Fig. 5a and b, respectively. Except for certain depth ranges, the sum of the components (grey line) compares reasonably well with the isobaric change (black line, $\theta_{z}$ and $S_{z}$ ), indicating that the decomposition has been successfully performed. The few discrepancies observed will be analyzed at the end of the section.

The surface and intermediate temperature and salinity variations are affected by both mechanisms: changes along neutral surfaces ( $\theta_{n}$ and $S_{\mathrm{n}}$, blue lines) and changes due to vertical displacement of the isoneutrals $\left(-\mathrm{N} \theta_{z}\right.$ and $-\mathrm{NS}_{z}$, red lines) (Fig. 5a and b). In the SASW stratum (pres- sure $<100 \mathrm{dbar}$ ) an increase of $0.7^{\circ} \mathrm{C}$ in temperature and 0.1 in salinity per decade is observed (Fig. $5 \mathrm{a}$ and b, respectively). This increase can also be discerned in Fig. 5c. These increases come together with a temperature-driven vertical displacement of the isoneutrals (Fig. 5a, red line). As the cruises took place in different seasons, the most plausible explanation for this shoaling is the different depths of the seasonal thermocline, being shallower in summer (2010) than in fall (1999).

In contrast to the upper layer, the SAMW and AAIW/AASW strata present a decadal decrease in temperature $\left(-0.6^{\circ} \mathrm{C}\right)$ and salinity $(-0.07)$ between 100 and $500 \mathrm{dbar}$ (Fig. 5a and b). These changes can also be observed in the average $\theta / S$-diagram for the AAIW/AASW (Fig. $5 \mathrm{c}$ ). The SAMW and AAIW/ASW strata occupy the same depth range, but the AAIW/ASW water mass spans over a higher area (Fig. 3). Hence, the decomposition shown in Fig. 5a and b mainly shows the behavior of the AAIW/AASW stratum and, therefore, it does not match with the increase in salinity observed in Fig. 5c for SAMW. In Fig. 5c the lines linking points of equal pressure for the SAMW and AAIW/AASW strata are not parallel to the isopycnals, indicating, as well, displacement of the isoneutrals' surfaces. This displacement is a deepening of the isoneutrals, mainly driven by the salinity. At the level of the UCDW no changes are observed (Fig. 5a-c). In contrast, the LCDW stratum shows a deepening of the isoneutrals driven by both temperature and salinity, although no changes along neutral surfaces are observed (Fig. 5a-c).

As seen in Fig. 5, the sum of the components compares reasonably well to the isobaric changes. However, a careful inspection reveals some discrepancies, which take place between 52 and $57^{\circ} \mathrm{W}$ and around $49.5^{\circ} \mathrm{W}$. These are the approximate locations of the SAF and PF. These gradients cause the vertical displacement of more than $200 \mathrm{dbar}$ for some isoneutrals, invalidating at these specific locations the linear expansion used to derive the proposed decomposition model, as was also found in the Gulf Stream by Arbic and Owens (2001). Thus, in Fig. 6 a sensitivity analysis is carried out by using the model of Bindoff and McDougall (1994) without the stations involved in the fronts, taking into account only the stations 18 (157) and 28 to 31 (145 to 142) for the 2010 (1999) survey. For the surface SASW water mass, the same behavior is found with or without fronts: an increase in temperature and salinity, though slightly higher in the decomposition done without the fronts $\left(0.9^{\circ} \mathrm{C}\right.$ and 0.15 vs. $0.7^{\circ} \mathrm{C}$ and 0.1 ), and a temperature-driven shoaling of the isopycnals. Likewise, in the range 100-500 dbar, where the SAMW and AAIW/AASW strata appear, the decomposition shows the same pattern: a slightly smaller decrease in temperature $\left(-0.4^{\circ} \mathrm{C}\right)$ and salinity $(-0.04)$ again accompanied by a salinity-driven deepening of the isopycnals.

In contrast, from $500 \mathrm{dbar}$ to the bottom two differences appear between both decompositions. The first one occurs between 500 and 2000 dbar: in both decompositions a slight 

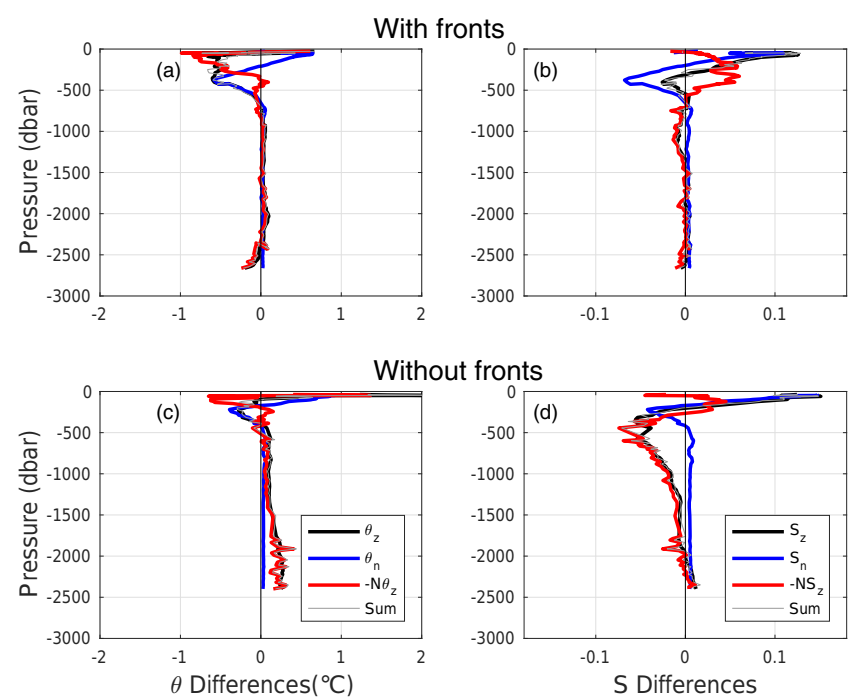

Figure 6. Comparison between the isobaric changes from 1999 to 2010 carried out with the whole dataset of each year (a, b, same as Fig. 5) and without the stations where the fronts are located (c, d). Isobaric changes from 1999 to $2010\left(\theta_{z}\right.$, black line) decomposed into changes along neutral surfaces $\left(\theta_{n}, S_{\mathrm{n}}\right.$, blue line) and changes due to the vertical displacement of isoneutrals $\left(-\mathrm{N} \theta_{z},-\mathrm{NS}_{z}\right.$, red line) for temperature $(\mathbf{a}, \mathbf{c})$ and salinity $(\mathbf{b}, \mathbf{d})$. The grey line shows the sum of both components.

increase in temperature and salinity is observed, but in the one carried out without the fronts it appears with a salinitydriven shoaling of the isopycnals. This depth range is mainly occupied by the UCDW stratum. The second significant change between both decompositions appears at the bottom of the profile, in the domain of the LCDW. As the stations east of MOC-Austral station 28 (ALBATROSS station 148) are shallower than $2400 \mathrm{dbar}$, this decomposition mainly shows the changes at station 18 . This station is located between both fronts, and shows a temperature-driven deepening of the isopycnals. The result in this stratum can be neglected, as one station cannot be considered statistically significant to provide representative results.

\subsection{Relative geostrophic mass transport changes}

Some significant differences are observed in the relative mass transport estimates for 1999 and 2010 across the hydrographic line along the Falkland Plateau (Table 1). The accumulated transports show the important role played by the SAF and PF in the relative mass transport across the section during both realizations (Fig. 7). During the MOCAustral cruise the SAF-associated jet is displaced westward and weakens by $14.7 \mathrm{~Sv}$ as compared with the ALBATROSS observations (Fig. 4 and Table 1). This affects the relative mass transport of all strata but LCDW. In contrast, the location of the PF remains unchanged between both cruises, but it strengthens up to $37.3 \mathrm{~Sv}$ during the MOC-Austral cruise (vs.

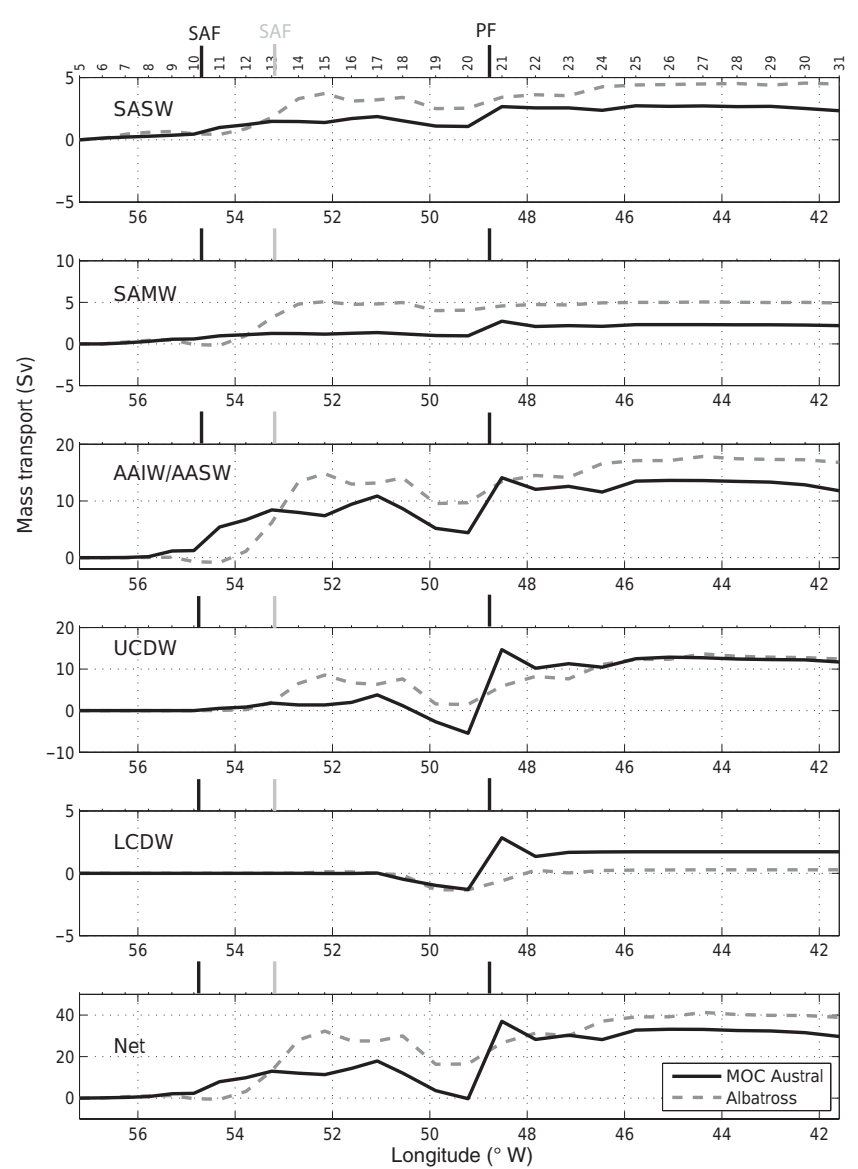

Figure 7. West-to-east accumulated relative geostrophic mass transport, computed across the ALBATROSS and MOC-Austral hydrographic sections. Station numbering and the front (SAF and PF) locations are displayed on the top axis. Note the different vertical scales.

the 24.9 Sv registered in the ALBATROSS survey), affecting the relative mass transports of all water strata. In 2010, immediately east of the PF, at $47.8^{\circ} \mathrm{W}$, a countercurrent appears carrying $-8.8 \mathrm{~Sv}$ to the south. Figure 8 shows the average SSH for the 2010 MOC-Austral cruise with the aim of understanding the source of this counter-flow. In this figure, the PF flows to the north around station 20 and partially diverts southward at station 23. This meandering of the PF has already been reported in previous studies (Naveira Garabato et al., 2002).

The relative net mass transport during the MOC-Austral cruise is $9.2 \mathrm{~Sv}$ weaker than in the ALBATROSS cruise as an outcome of a more intense SAF in 1999. SASW, AAIW/AASW and UCDW present lower values in 2010 than in 1999, the surface and intermediate strata being the ones with the highest decadal transport differences (Fig. 7 and Table 1). This is presumably due to a weaker SAF in 2010 $(17.9 \mathrm{~Sv})$ than in 1999 (32.6 Sv) (Table 1). The SAF does not have a contribution from the LDCW stratum due to the shal- 


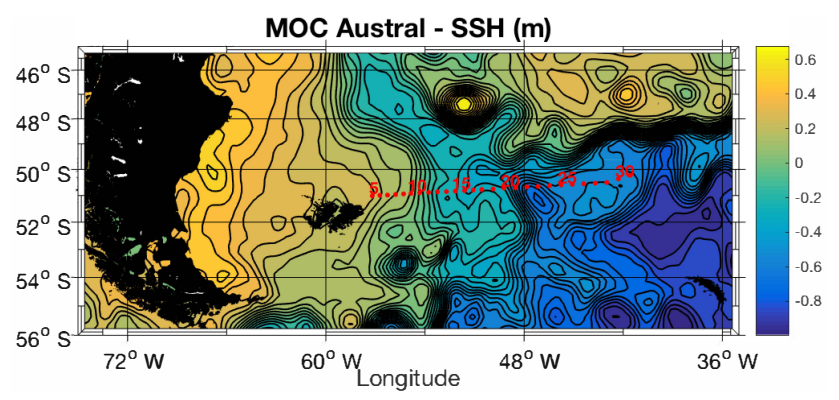

Figure 8. AVISO SSH for the MOC-Austral cruise. Isolines have a separation of $5 \mathrm{~cm}$.

low bathymetry. Thus, the only northward contribution to this stratum is done by the PF, which is stronger in 2010 than in 1999 from the SAMW stratum to the bottom. The total mass transports of the PF are 37.3 Sv in 2010 vs. 24.9 Sv in 1999.

Figure 9 exhibits the vertical structure of the calculated mass transport in the different layers, which define each water mass. The geostrophic mass transports in the ALBATROSS (1999) and MOC-Austral (2010) hydrographic cruises behave likewise across the water column. The mass transports from the surface to the UCDW stratum are affected by a noticeable northward net mass transport decrease of $10.6 \mathrm{~Sv}$ from 1999 to 2010. In contrast, the LCDW exhibits an increase of $1.4 \mathrm{~Sv}$ in the northward flow in 1999 and 2010.

To put all the estimated mass transports into context, the monthly 1993-2016 averaged geostrophic velocities from AVISO are interpolated to the station pairs of both cruises and integrated by using the stations' distance and the average depth of the SASW stratum $(50 \mathrm{~m})$. This is shown in Fig. 10, where the 1993-2016 average of all Februaries (Aprils) is contrasted with the estimated relative transport of the MOCAustral (ALBATROSS) upper stratum. It is seen that there is no significant climatological difference between the estimations of both months. Hence, the positions and transports (expressed as mean \pm standard deviation) of the $\mathrm{SAF}$ and $\mathrm{PF}$ in the AVISO-derived transports are $2.5 \pm 0.5 \mathrm{~Sv}$ at the longitudinal range $52.97-56.96^{\circ} \mathrm{W}$ and $1.1 \pm 0.7 \mathrm{~Sv}$ at 47.49 $51.34^{\circ} \mathrm{W}$, respectively. The SAF AVISO estimated transport is approximately the average between the SASW transports of ALBATROSS (3.2 Sv) and MOC-Austral (1.9 Sv). The PF observed in the AVISO data covers a wider range of longitudes than the ones of the hydrographic surveys. Its transport is slightly smaller than for the ALBATROSS cruise $(2.0 \mathrm{~Sv})$ and non-significantly different from MOC-Austral $(1.6 \mathrm{~Sv})$ at the SASW stratum (Table 1).

\section{Discussion and conclusions}

The decadal differences in the Falkland Plateau are studied from full-depth hydrographic data collected during the AL-

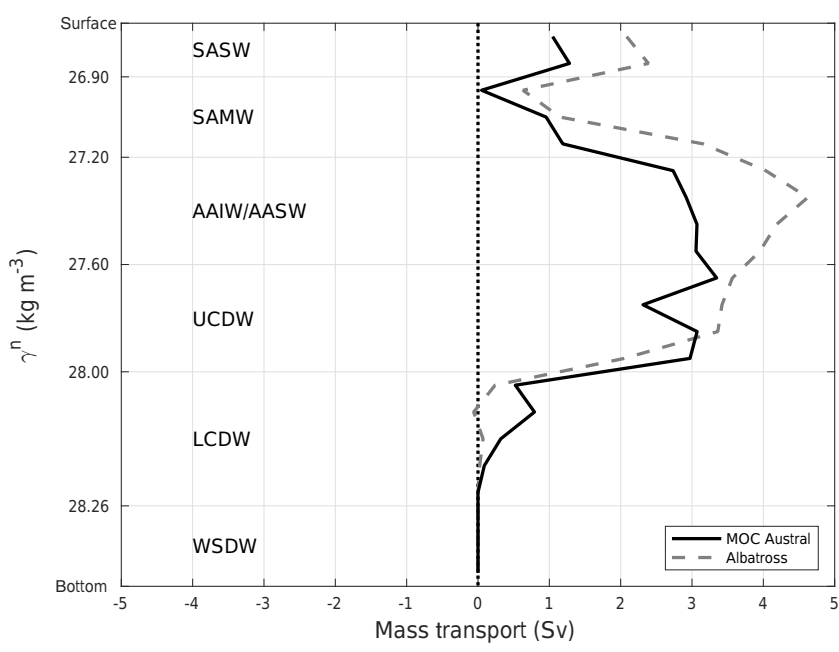

Figure 9. Relative geostrophic mass transport per layer across the ALBATROSS and MOC-Austral sections.

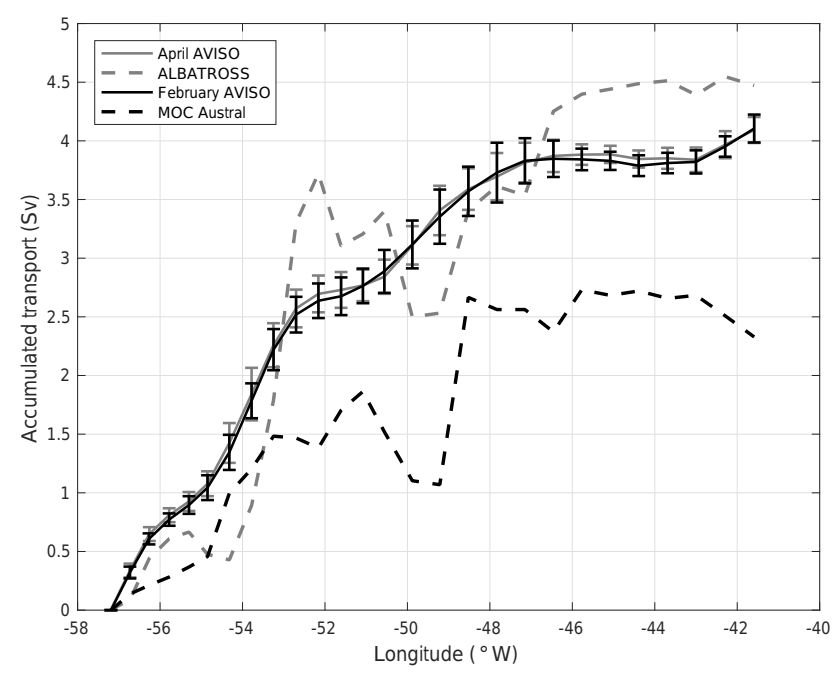

Figure 10. West-to-east accumulated relative geostrophic mass transport from AVISO averaged from 1993 to 2016, together with their standard deviations: April (grey solid line) and February (black solid line). For this calculation, the depth of $50 \mathrm{~m}$ has been considered to compute the mass transport that corresponds to the SASW stratum. Dashed lines are the west-to-east accumulated relative geostrophic mass transports shown in Fig. 7 for the SASW for ALBATROSS (grey) and MOC-Austral (black) carried out in April and February, respectively.

BATROSS (April 1999) and MOC-Austral (February 2010) cruises. Water mass changes are explored in terms of changes along neutral surfaces and changes due to vertical displacements of $\gamma^{n}$ surfaces, applying the model proposed by Bindoff and McDougall (1994). Variability in the SAF and $\mathrm{PF}$ location and mass transport is inferred from relative geostrophic velocities estimated by using the sea bottom as the level of no motion. 
(a) Winter average

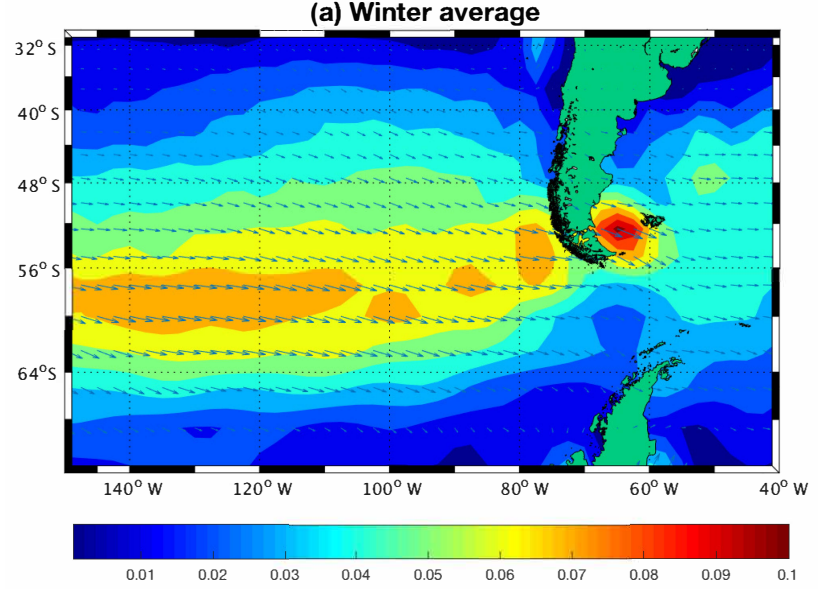

(b) Winter anomaly 1998

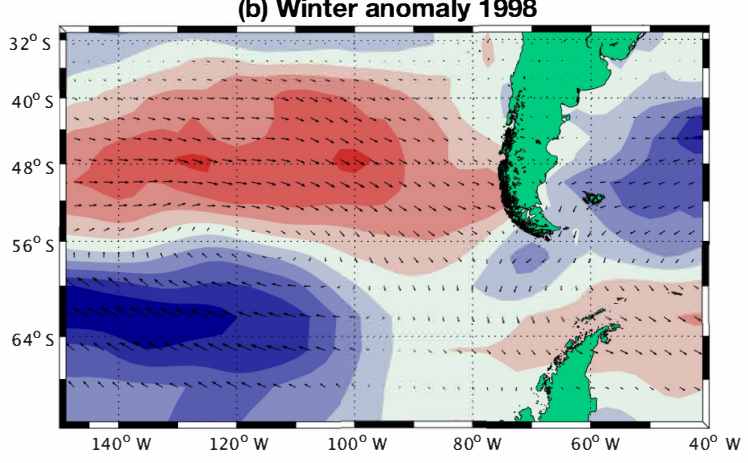

(c) Winter anomaly 2009

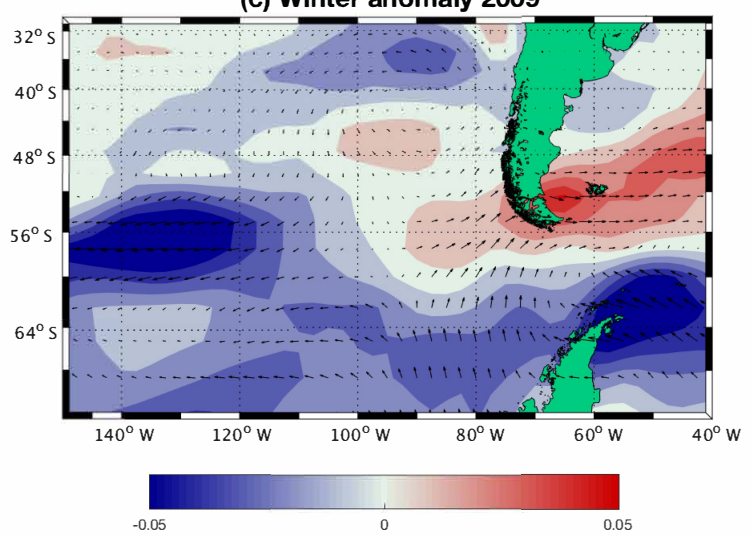

Figure 11. Maps of NCEP-NCAR (a) winter (July-September) mean wind stress in Pa (arrows; color indicates magnitude) for the time period 1998-2010. (b) Winter wind stress anomaly (Pa) for the year 1998. (c) Same as (b) but for 2009.

The SASW stratum presents a wider range of salinities and temperatures in 1999 than in 2010, as shown in the $\theta / S$ diagram. In spite of this, the $\theta / S$ isobaric changes show an increase in surface temperatures and salinities matching the Bindoff and McDougall (1994) model's result for changes along neutral surfaces. The model also exhibits shoaling of the isopycnals. The most plausible source of these differences is the fact that the hydrographic cruises took place in different seasons (ALBATROSS in austral fall and MOCAustral in austral summer). Hence, the seasonal thermocline has probably changed its depth due to the different seasonal heating and precipitation. The scarce in situ observations in the area do not allow any further conclusions.

SAMW expands over a larger depth range and presents a wider range of salinities in 1999 than in 2010 (Figs. 2 and 4). In contrast, the $\theta / S$ diagram and isobaric changes for the AAIW/AASW stratum show a decrease in temperature and salinity in 2010 when the AAIW/AASW occupies a higher depth range (Figs. 2 and 4). As both Bindoff and McDougall (1994) model estimations (with and without frontal zones) agree in that the changes in the intermediate strata are due to the displacement of $\gamma^{n}$ surfaces, some changes are likely to have occurred between 1999 and 2010 in the Falk- land Plateau. The Bindoff and McDougall (1994) model reveals a deepening of the isoneutrals at these levels, where the AAIW/AASW stratum occupies a higher depth range than SAMW. An explanation for changes in those strata can be found in Naveira Garabato et al. (2009). Figure 11a shows the mean wind stress of the winters in the period 19982010. This figure is analogous to Fig. 11a of Naveira Garabato et al. (2009). In the climatological mean a continuous wind stress magnitude spreads west from South America (Fig. 11a). Figure $11 \mathrm{~b}$ and $\mathrm{c}$ exhibits the previous winter anomalies to the ALBATROSS and MOC-Austral cruises, respectively. These anomalies look very different between themselves. Figure $11 \mathrm{~b}$ shows a large eastward (positive) wind stress anomaly in the South Pacific. Naveira Garabato et al. (2009) suggest that this structure causes a shift in the SAMW formation area. This matches with the changes observed in Figs. 2 and 4, where the SAMW stratum area is reduced. It also agrees with the isobaric changes reported, a decrease in temperature of $0.8^{\circ} \mathrm{C}$ and an increase in salinity of 0.02 from 1999 to 2010.

Naveira Garabato et al. (2009) also reported that the 1998 wind stress anomaly pattern shown in Fig. $11 \mathrm{~b}$ generates a shutdown of the AAIW formation. Due to this, a minimum 
of temperatures $\left(<1.2{ }^{\circ} \mathrm{C}\right)$ and salinities (ca. 34) can be observed only for the MOC-Austral cruise in Figs. $1 \mathrm{~b}$ and $2 \mathrm{~b}$. The shutdown of the AAIW formation in 1998 is responsible for the observed changes from 1999 to 2010 at this stratum. Across the decade, the AAIW/AASW stratum increases the spanning area at intermediate layers and suffers a decrease of $0.6^{\circ} \mathrm{C}$ in temperature and of 0.07 in salinity, which is accompanied by a deepening of the isoneutrals. Wind-driven changes in the ACC isobaric surfaces were also observed in Böning et al. (2008), where a deepening of the isopycnals of 27.2 and $27.4 \mathrm{~kg} \mathrm{~m}^{-3}$ is described. The reported decrease of 0.07 in salinity agrees with the decadal trend of the ACC at 300-500 dbar observed in Böning et al. (2008), shown in their Fig. 4. In contrast, they find an increase in temperature at the same layer, probably due to the contribution of other intermediate waters to the ACC.

The SAF and PF undergo some displacements and variations in intensity between 1999 and 2010. The SAF in 1999 is observed at $52.2-54.8^{\circ} \mathrm{W}$ with a relative mass transport of $32.6 \mathrm{~Sv}$ and, while it is wider in 2010, reaching the Falkland Islands, it weakens to roughly half of the transport $(17.9 \mathrm{~Sv})$. The SAF is the main path for the northward flow of SASW, SAMW and AAIW/AASW into the Atlantic Basin. The PF also contributes to this northward flow, being important for the UCDW and LCDW. The PF in 1999 is located in the longitudinal range $49.8-44.4^{\circ} \mathrm{W}$ carrying $24.9 \mathrm{~Sv}$, while in 2010 it narrows, centering on $49.9-49^{\circ} \mathrm{W}$ and strengthening to $37.3 \mathrm{~Sv}$. The PF in 2010 carries the highest relative northward transport of the study area, but nearly $8 \mathrm{~Sv}$ of it recirculate back southward, as seen in the SSH image. This meandering of the PF was also observed in Naveira Garabato et al. (2002). The average of the AVISO climatological seasonal transport is non-significantly different between February and April. Thus, the observed changes in transport are due to interannual variability.

The abrupt decrease in the SAF to almost half of its transport between both decades has it source in the different wind patterns observed in Fig. 11 and described in Naveira Garabato et al. (2009). The changes in these westerly winds that circle Antarctica are driven by the Southern Annular Mode (SAM). Combes and Matano (2014) analyze the 1990 to 2012 trend of the SAM and its relation to the Falkland Current (which is nourished from the SAF). In their study they report a decrease in the Drake Passage transports and in the Falkland Current after 1999-2000 as a consequence of a weakening of the westerly winds.

To conclude, a seasonal change in the thermocline is observed in the surface layer. Changes in the westerly winds driven by the increasing trend of the SAM (Combes and Matano, 2014; Naveira Garabato et al., 2009) have an important effect on the water masses and transports observable in the Falkland Plateau. The intermediate water masses of the study area seem to be very sensitive to the wind conditions existing in their formation area. Hence, in 2010 an increase (decrease) in the AAIW/AASW (SAMW) stratum is observed together with a cooling, freshening and deepening of the isopycnals at this level. The CDW layers do not exhibit any significant change in the water mass properties, being the most homogenous water mass. However, the LCDW exhibited a temperature- and salinity-driven deepening of the isopycnals from 1999 to 2010 . The net transport is 9.2 Sv weaker in 2010 than in 1999 and is mainly explained by a decrease in the transport of the SAF. Fronts change their width and strength between cruises, the SAF/PF being wider/thinner in 2010 and weaker/stronger than in 1999. Changes in the water masses, position and transport contribution of the SAF and PF to the north directly affect the BrazilMalvinas Confluence Zone, which moves to the south when the SAF weakens (Combes and Matano, 2014). This strong frontal zone is critical for the Southern Hemisphere meridional overturning, is where the deep western boundary separates from the Argentinian basin, and is a high-energy area that contributes to the active water mass transformation (Mason et al., 2017).

Data availability. The data are already being published at https://doi.org/10.17882/50171.

Competing interests. The authors declare that they have no conflict of interest.

Acknowledgements. This study has been performed thanks to MOC2 (CTM2008-06438-C02-02/MAR) and Sevacan (CTM201348695), financed by the Spanish Government. The ALBATROSS cruise was funded by a Natural Environment Research Council grant (GR3/11654). This work was completed while M. Dolores Pérez-Hernández was a PhD student in the IOCAG Doctoral Programme in Oceanography and Global Change. The authors would like to thank David Sosa, Rayco Alvarado and all the scientific team and crew onboard the BIO Hespérides for their hard work at sea during the MOC-Austral cruise.

Edited by: Mario Hoppema

Reviewed by: two anonymous referees

\section{References}

Arbic, B. K. and Owens, W. B.: Climatic warming of Atlantic intermediate waters, J. Climate, $14, \quad 4091-4108, \quad$ https://doi.org/10.1175/15200442(2001)014<4091:CWOAIW>2.0.CO;2, 2001.

Arhan, M., Naveira Garabato, A. C., Heywood, K. J., and Stevens, D. P.: The Antarctic Circumpolar Current between the Falkland Islands and South Georgia, J. Phys. Oceanogr., 32, 1914-1931, https://doi.org/10.1175/15200485(2002)032<1914:TACCBT>2.0.CO;2, 2002.

Bindoff, N. L. and McDougall, T. J.: Diagnosing climate change and ocean ventilation using hydrographic data, J. 
Phys. Oceanogr., 24, 1137-1152, https://doi.org/10.1175/15200485(1994)024<1137:DCCAOV>2.0.CO;2, 1994.

Böning, C. W., Dispert, A., Visbeck, M., Rintoul, S. R., and Schwarzopf, U.: The response of the Antarctic Circumpolar Current to recent climate change, Nat. Geosci., 1, 864-869, https://doi.org/10.1038/ngeo362, 2008.

Combes, V. and Matano, R. P.: Trends in the Brazil/Malvinas Confluence region, Geophys. Res. Lett., 41, 8971-8977, https://doi.org/10.1002/2014GL062523, 2014.

Cunningham, S. A., Alderson, S. G., King, B. A., and Brandon, M. A.: Transport variability of the Antarctic Circumpolar Current in Drake Passage, J. Geosphys. Res.-Oceans., 108, 8084, https://doi.org/10.1029/2001JC001147, 2003.

Dibarboure, G., Lauret, O., and Mertz, F.: SSALTO/DUACS User Handbook: (M)SLA and (M)ADT near-real time and delayed time products, AVISO Rep. CLS-DOS- NT 06-034, Issue 4.4, SALP-MU-P-EA-21065-CLS, 2015.

Donohue, K. A., Tracey, K. L., Watts, D. R., Chidichimo, M. P., and Chereskin, T. K.: Mean Antarctic Circumpolar Current transport measured in Drake Passage, Geophys. Res. Lett., 43, 1176011767, https://doi.org/10.1002/2016GL070319, 2016.

Ganachaud, A. and Wunsch, C.: Large-scale ocean heat and freshwater transports during the World Ocean Circulation Experiment, J. Climate, 16, 696-705, https://doi.org/10.1175/15200442(2003)016<0696:LSOHAF>2.0.CO;2, 2003.

Mason, E., Pascual, A., Gaube, P., Ruiz, S., Pelegrí, J. L., and Delepoulle, A.: Subregional characterization of mesoscale eddies across the Brazil-Malvinas Confluence, J. Geophys. Res.-Oceans, 122, 3329-3357, https://doi.org/10.1002/2016JC012611, 2017.

Naveira Garabato, A. C., Heywood, K. J., and Stevens, D. P.: Modification and pathways of Southern Ocean Deep Waters in the Scotia Sea, Deep-Sea Res. Pt. I, 49, 681-705, https://doi.org/10.1016/S0967-0637(01)00071-1, 2002.
Naveira Garabato, A. C., Stevens, D. P., and Heywood, K. J.: Water mass conversion, dluxes, and mixing in the Scotia Sea diagnosed by an inverse model, J. Phys. Oceanogr., 33, 2565-2587, https://doi.org/10.1175/15200485(2003)033<2565:WMCFAM>2.0.CO;2, 2003.

Naveira Garabato, A. C., Jullion, L., Stevens, D. P., Heywood, K. J., and King, B. A.: Variability of Subantartic Mode Water and Antarctic Intermediate Water in the Drake Passage during the late-twentieth and early-twenty-first centuries, J. Climate, 22, 3661-3688, https://doi.org/10.1175/2009JCLI2621.1, 2009.

Orsi, A. H., Whitworth III, T., and Nowlin Jr., W. D.: On the meridional extent and fronts of the Antarctic Circumpolar Current, Deep-Sea Res. Pt. I, 42, 641-673, https://doi.org/10.1016/09670637(95)00021-W, 1995.

Peterson, R. G.: The boundary currents in the western Argentine Basin, Deep-Sea Res., 39, 623-644, https://doi.org/10.1016/0198-0149(92)90092-8, 1992.

Peterson, R. G. and Whitworth III, T.: The subantarctic and polar fronts in relation to deep water masses through the southwestern Atlantic, J. Geophys. Res., 94, 10817-10838, https://doi.org/10.1029/JC094iC08p10817, 1989.

Smith, I. J., Stevens, D. P., Heywood, K. J., and Meredith, M. P.: The flow of the Antarctic Circumploar Current over the North Scotia Ridge, Deep-Sea Res. Pt. I, 56, 14-28, https://doi.org/10.1016/j.dsr.2009.10.010, 2010.

Trathan, P. N., Brandon, M. A., Murphy, E. J., and Thorpe, S. E.: Transport and structure within the Antarctic Circumpolar Current to the north of South Georgia, Geophys. Res. Lett., 27, 17271730, https://doi.org/10.1029/1999GL011131, 2000.

UNESCO: The practical salinity Scale 1978 and the international equation of state of seawater 1980, Techn. Pap. mar. sci, 36, 25 pp., 1981. 